Please cite this article as:

Manfredi Latilla V., Frattini F., Messeni Petruzzelli A. and Berner M. (2019)

Knowledge management and knowledge transfer in arts \& crafts organizations: evidence from an exploratory multiple case-study analysis

Journal of Knowledge Management, Vol. 23 (7), pp. 1335-1354.

DOI: https://doi.org/10.1287/orsc.11.5.538.15204 


\title{
Knowledge management and knowledge transfer in arts \& crafts organizations: evidence from an exploratory multiple case-study analysis
}

\begin{abstract}
.
Purpose - The present exploratory study discusses the results of a multiple case study of 5 Italian arts \& crafts organizations, to explore how knowledge is transferred within such organizations and how the transfer process is related to and impacts the creation of organizational artifacts, with a focus on the role of craftsmen in the knowledge transfer process. The issue of knowledge transfer in arts and crafts organizations gains importance because in this specific setting products are mostly handmade, making the knowledge of craftsmen of extreme importance for organizational success, as well as knowledge transfer vital for organizational survival in the long run.

Design/Methodology/Approach - In answering the research question - i.e. how in the context of arts \& crafts organizations knowledge can be managed and transferred becoming a real source of competitive advantage, - we aim at enriching existing theory with new insights from real-world cases. Since no prior empirical research on the relationship among knowledge, knowledge transfer and the role of craftsmen is available, an exploratory, qualitative research design seems advisable to study the phenomenon in detail. In setting up a multiple case study, we established a sampling frame of criteria associated with the theoretical background and research interest of our study: the case firms had to be arts \& crafts organizations well known for the high quality and value of their artifacts and with a solid reputation for preserving the tradition and the uniqueness of their manufacturing processes. Organizations were finally selected based on convenience sampling, i.e. for their alignment with the interests and activities of the private foundation sponsoring the research. Five organizations meeting these criteria were identified, contacted and studied in this research.
\end{abstract}

Findings - The study illuminates the importance of craftsmen within arts \& crafts organizations, whose knowhow and technical skills are high valued by colleagues, by the market (customers), within the society and the territory where they operate. The knowledge acquired and retained by the craftsmen becomes therefore crucial for the survival of the arts \& crafts organizations and for their profitability in the long term, and its transfer requires a proper codification policy in order to allow next generation of craftsmen to retain the skills and knowhow of former craftsmen.

Research limitations/implications - From the empirical investigation it has emerged the lack of a common knowledge transfer process to different organizations, since the process itself is influenced by the organizational structure, the management style of the organization owner (very often a family which retains the totality of the organization shares/quota), the social context and the territory where the organization is located, as well as the target market and the specific niche of customers who buy the organization's products. It has also emerged a certain unawareness at the managerial level of the strategic relevance of the craftsmen knowhow and skills and of how to practically and effectively transfer their knowledge to a future generation of young craftsmen.

Practical implications - A common result that has emerged from our analysis is that craftsmen play a crucial role for the success of arts \& crafts organizations, since this kind of organization gives the maximum relevance to their individual abilities, knowhow and skills to generate wealth and employment through the creation and production of exclusive, high value products, hence it is crucial to preserve and transfer properly craftsmen knowhow and skills. This result is relevant for the world of practice, where the lack of a codified knowledge transfer process within arts \& crafts organizations may hamper the survival of such organizations in the long run. Hence, we believe the present study may enrich the debate on the conceptualization and codification of knowledge transfer practices among arts \& crafts organizations, where in our analysis has emerged the importance of creating ad hoc repositories and procedures to codify and favor such transfer, as well the role of training as a powerful tool to guide the young generation of craftsmen in performing properly their tasks in an organized and professional manner.

Originality/value - Despite the interest of many authors toward both knowledge management and transfer within the creative industry, there is a lack of studies aimed at linking systematically these two research areas. This is a relevant issue since knowledge in creative industries mainly refers to the traditions and values at the basis of an organization's culture, tends to manifest itself in a tacit way and is difficult to analyze because it mainly exists in the mind of craftsmen as the result of their working experience. Nevertheless, tacit knowledge becomes a determinant of organizational performance, making its transfer crucial for organizational survival and growth. 
This study is an attempt to fill this gap by illuminating the relationship between knowledge and the role played by craftsmen in the knowledge transfer process.

Keywords: knowledge management, knowledge transfer, arts \& crafts organizations, craftsmen

\section{Introduction}

This study analyses and discusses five longitudinal case studies in which the authors have investigated how, in a specific subset of the creative industry, i.e. the arts \& crafts organizations, knowledge can be systematized and transferred, becoming a real source of competitive advantage.

With "creative industry", to the extent of the present contribution, we refer to the definition given by the Creative Industries Task Force Mapping Document (2000), according to which the creative industry refers to "activities that have their origins in individual creativity, skill and talent and which have the potential for wealth and job creation through the generation and exploitation of intellectual property"; while with "arts\& crafts organizations" is intended a specific subset of the creative industry, mainly related to the production of high symbolic value artifacts, resulted of largely manual (handmade) processes obtained thorough the work of high-skilled craftsmen.

To the extent of the present study, the issue of knowledge transfer in arts and crafts organizations gains importance because in this specific setting products are mostly handmade, making the knowledge of craftsmen of extreme importance for the organizational success, as well as knowledge transfer between craftsmen, their team of assistants and next generation of employees vital for organizational survival in the long run. In the arts $\&$ crafts industry indeed, more than in the creative industry in general, the analysis of knowledge and knowledge transfer is important for its tacit connotation, though this kind of knowledge is hard to connect to performance results, because it mainly exists in the mind of craftsmen as the result of their working experience (Høgseth, 2013).

Despite the interest of many authors toward both knowledge management and transfer within the creative industry (Lampel and Germain, 2016; Klamer, 2012; King et al., 2008; Tsoukas, 2005; Lambooy, 2002; Boisot, 2002; Nonaka and Teece, 2001; Rodgers et al. 2000; Dixon, 2000; Seltzer and Bentley, 1999), there is a lack of studies aimed at linking systematically these two research areas (Manfredi Latilla et al., 2018). This is a relevant issue since knowledge in creative industries mainly refers to the traditions and values at the basis of an organization's culture (Schein, 2004), tends to manifest itself in a tacit way (Venkitachalam and Bush, 2012) and is difficult to analyze because it mainly exists in the mind of individuals as the result of their working experience (Harlow, 2008) not expressed in an explicit form (Von Krogh et al., 2000). Tacit knowledge in arts \& crafts organizations is hard to articulate and requires observation, demonstration and experience for its transfer (Nonaka and Takeuchi, 1995). Nevertheless, it has a real tangible impact on organizational behaviors and becomes a determinant of organizational performance (Nonaka and Teece, 2001; Schein, 1996; Byles et at., 1991; Koberg and Chusmir, 1987; Barney, 1986), making its transfer crucial for organizational survival and growth. 
At the core of the knowledge transfer process within the subset of arts \& crafts organizations are the craftsmen, real "masters of art" capable of using the "intelligence of the hand", the "passion of the heart" and the "creativity of the mind" (i.e., their "tacit knowledge") (Shils, 1981; Schein, 2004) to acquire an aura of excellence and to confer exclusivity to products that enjoy a unique positioning in international markets (Sennett, 2008). Craftsmen's knowledge can hence be considered a real financial resource (Davenport and Prusak, 2000) so that underlining the value of such knowledge and its transfer becomes relevant for the survival and growth of arts \& crafts organizations. Nevertheless, in the contest of arts \& crafts organizations there is a lack of practical understanding of the relationship between knowledge and the role of craftsmen in the knowledge transfer process (Manfredi Latilla et al., 2018). See figure 1 for a graphical visualization of the research context.

\section{Insert Figure 1}

With this regard, the present empirical contribution is built on the analysis of five case studies with the aim of investigating how knowledge transfer is effectively realized and which is the role of craftsmen in the knowledge transfer process. A qualitative approach has been chosen since it facilitates the understanding of complex phenomena such the ones under investigation (Yin, 2009; Fleming, 2001; Levinthal, 1997) and helps enriching existing theory with new insights from real-world cases to make theoretical generalization to the existing body of research concerned with knowledge transfer in the specific subset of arts \& crafts organizations. From the analysis, several arguments of debate relevant to the craftsmen's knowledge, their role within arts \& crafts organizations and the overall knowledge transfer process have been derived, which will be discussed in section 4 below. Overall, the study is structured as follow: section 2 reviews the literature on knowledge management and transfer within arts \& crafts organization; section 3 describes the methodology adopted and the structure of the data collection phase; section 4 provides and discusses findings while section 5 concludes the multiple case study analysis.

\section{Literature review}

\subsection{Knowledge management and transfer}

Knowledge management and transfer are popular topics in several extant literatures including strategic management and organizational theory as well as information systems (De Massis et al., 2016; Joia and Lemos, 2010; Kumar and Ganesh, 2009; Foss and Pedersen, 2002; Alavi and Leidner, 2001). Knowledge, indeed, is a primary asset in modern economy, specifically when it refers to creative industry, where it is mainly the result of individual inspirations, abilities and talents, able to create wealth and employment through the generation and exploitation of intellectual skills and craftsmanship abilities (Hennekam and Bennett, 2017; Lampel and Germain, 2016; Stock et al., 2013; Lord and Ranft, 2000; O'Reilly et al., 1991). 
It is in the mid-1990s that the theme of knowledge management and transfer became relevant in research on management and organizational behavior. Pulic (1998), for example, stressed the need for organizations to efficiently and effectively locate, capture and share their knowledge and skills to maintain competitiveness. Seltzer and Bentley (1999) emphasized the role of knowledge as a primary resource of the "creative age" (as the authors define the current historical period) and analyzed the internal profound changes the organizations require to survive this "creative age". Osterloh and Frey (2000) identified knowledge, knowledge generation and knowledge transfer as essential for the acquisition of organizational competitive advantages, while Chen and Fong (2015) stated that "knowledge management is a discipline possibly impacting organizational competitiveness and innovation”. Specifically, managing organizational knowledge involves developing new content or replacing existing content within the organization's tacit and explicit knowledge (Pentland 1995). Through social and collaborative processes as well as individual's cognitive processes, knowledge is created, shared, amplified, enlarged and justified in organizational settings (Nonaka 1994). This model views organizational knowledge management as involving a continuous interplay between the tacit and explicit dimensions of knowledge and a growing spiral flow as knowledge moves through individual, group and organizational levels (Alavi and Leidner, 2001).

Within the specific subset of arts \& crafts organizations, then, the knowledge-based activities of craftsmen, their unique skills and capabilities are primary functions having a huge impact on the creation of competitive advantage through the development of exclusive handmade artifacts. To this extent, an organization owning and managing effectively its knowledge as well as recognizing it as a critical resource to be transferred, can build a solid and recognizable corporate and brand identity, leveraging on a unique heritage made of quality and creativity (Davenport and Prusak, 2000). Knowledge, therefore, can be considered a strategic organizational resource, to be properly managed and transferred among the employees and to the new generation of employees.

Knowledge transfer, on the other hand, pertains to an articulated process of sharing values, purposes, common belief as well as a specific know-how embedded in the organizational processes and in the ability of its workers (Dasgupta and David, 1994; David and Foray, 1995; Cowan and Foray, 1996; Ajith Kumar and Ganesh, 2009). Some scholars have defined knowledge transfer as the process through which one unit (e.g. group, department, or division) is affected by the experience of another (Argote and Ingram, 2000; Inkpen and Tsang, 2005; Watson and Hewett, 2006). Other scholars (i.e., Darr and Kurtzberg (2000, p. 29) have defined knowledge transfer as an event through which one entity learns from the experience of another, suggesting thereby that the effect of one unit on another is in terms of the learning that the second unit experiences. According to Foss and Pedersen (2002), knowledge transfer is not an in toto replication of knowledge in a new location. Rather, it involves the modification of some existing knowledge to a different context - "what is transferred is (usually) not the underlying knowledge but rather applications of this knowledge in the form of solutions to specific problems" (Foss and Pedersen, p. 54). Therefore, knowledge transfer can be interpreted as "a process of exchange of 
explicit or tacit knowledge between two agents, during which one agent purposefully receives and uses the knowledge provided by another" (Ajith Kumar and Ganesh, 2009, p. 163).

Several other scholars (e.g., Klammer and Gueldenberg, 2018; Savino et al., 2017; Cohen and Bacdayan, 1994; Huber, 1991; Levitt and March, 1988; Nelson and Winter, 1982) have underlined the importance of understanding how employees acquire, learn, process, retain, unlearn, codify and finally transfer their knowledge and know-how, especially when tacit, with other employees within the organization and eventually with other organizations. This because the knowledge management approach adopted by companies as well as their organizational structures are relevant elements for the success of tacit knowledge transfer (Joia and Lemos, 2010). Tacit knowledge, indeed, on the one hand can arise to the level of a proper organizational know-how, becoming a real source of competitive advantage relevant to be transferred (Grant, 1996). On the other hand, being not-codified, it exists only in the minds of individuals as the result of their working experiences and is linked to their understanding of the contexts of action, feelings and insights that can hardly be understood by those who do not share that same working experience (Foos et al., 2006).

\subsection{Knowledge transfer in arts \& crafts organizations}

Argote and Ingram (2000) provided a knowledge transfer framework which holds that knowledge in an organization is embedded in three basic elements - its members, tools, and tasks - and the various subnetworks formed by combining or crossing these elements. According to the framework of Argote and Ingram, knowledge transfer through the movement of members (employees) refers to transfer that happens when knowledge that resides in a person is transferred to another person. Knowledge transfer through the movement of tools (i.e., technology and industrial equipment) is reflected in work on technology transfer (Berry, 2003). Knowledge transfer through the movement of tasks usually happens when an existing firm opens a branch, a subsidiary or a franchise outlet.

In the context of arts \& crafts organizations, knowledge transfer is mainly realized through the movement of members and tools. With this regard, the role of craftsmen has become central in academic research since more than a decade, when scholars studying the organizational decision making process started to attribute great relevance to the role of knowledge and its transfer, emphasizing the prominent role covered by craftsmen in the knowledge transfer process (Argote and Ingram, 2000). Knowledge, in this contest, is mainly tacit and pertains to the traditions of the organization itself (Messeni Petruzzelli and Albino, 2012) as well as to the long-standing traditions and practices of certain communities, which have often been passed orally from generation to generation (Shils, 1981). It is hence important to enable and facilitate the transfer of craftsmen's knowledge, since such knowledge becomes a powerful and unique source of organizational performance in the present time, allowing arts \& crafts organizations to leverage on their reservoir of knowledge, traditions (both internal and related to the territory the organizations belong to) and on the skills of their craftsmen to foster growth and market visibility (Kotlar et al., 2018; Messeni Petruzzelli and Savino, 2014; Heeley and Jacobson, 2008). Specifically, it is in the 
context of arts \& crafts organizations that craftsmen play a central role in the knowledge creation and transfer, and the way they interact with each other helps generate new organizational artifacts, i.e. all the visible, audible and tangible aspects of the organizational culture, which can be considered the result of the employees' knowledge inside the organization (Nonaka and Takeuchi, 1995; Pratt and Rafaeli, 2005, 1997; Kaufmann, 2004). Craftsmen's knowledge, in its essence of being mainly tacit, is what gives exclusivity and uniqueness to their work (Sennett, 2008). It is built on traditions extensively validated and transferred over time, a key element that allows arts \& crafts organizations to develop innovation characterized by uniqueness and to produce exclusive artifacts, to the point that the osmosis between tradition and innovation appears to be an essential element (Kotlar et al., 2018; De Massis et al. 2016; Di Minin and Faems, 2013). Knowledge-based activities of craftsmen, hence, have a huge impact on the creation of competitive advantage through the development of unique and exclusive artifacts.

\section{Methodology}

In answering the research question, i.e. how in the context of arts \& crafts organizations, knowledge can be managed and transferred becoming a real source of competitive advantage, we chose to adopt an exploratory, qualitative research design to study the phenomenon in detail since no prior empirical research on the relationship among knowledge, knowledge transfer the role of craftsmen is available (Eisenhardt, 1989). Thus, we aim at enriching existing theory with new insights from real-world cases comparing five different organizations in a search for similarities and differences to finally make theoretical generalization to the existing body of research concerned with knowledge transfer in the specific subset of creative industry, i.e. arts \& crafts organizations. That is, the findings can be used to further develop theoretical ideas regarding knowledge, knowledge transfer and the role of craftsmen in arts \& crafts industry, but not to make generalization claims to any populations of firms or markets.

In setting up the multiple case study (Yin, 2009), we established a sampling frame of criteria associated with the theoretical background and research interest of our study: the case firms $i$ ) had to be arts \& crafts organizations well known for the high quality and value of their artifacts; ii) had to have a solid reputation for preserving the tradition and the uniqueness of their manufacturing processes. Organizations were finally selected for convenience, i.e. for their alignment with the interests and activities of the private foundation sponsoring the research. Five organizations meeting these criteria were identified and contacted (i.e., Organization R; Organization V; Organization B; Organization C; Organization RE., by the initial letters of each organization). For confidentiality reasons, their names are disguised. Annex 1 provides a brief description of the selected organizations.

\subsection{Data analysis}

Data were gathered through semi-structured interviews with executives, craftsmen (i.e., owner of the tacit knowledge within the organizations) and young employees (i.e., employees with less than 3 years 
of working experience in the organization and less than 32 years old). Interviews with executives were finalized to gain a strategic overview of the organization management with regards to the exclusivity of the goods sold, the strength of the brand and its impact on the business. Interviews with craftsmen were intended to analyze the knowledge transfer process at operational level; interviews with young employees were intended to understand how each organization transfers its (tacit) knowledge to young generation to preserve over time the value of its traditions and heritage. Overall, interviews aimed at investigating the role of the craftsmen within each organization and the related knowledge transfer process.

Interviews were performed over a 5 months period in the first semester of 2018 and were transcribed verbatim to allow for subsequent analysis and complemented through extensive desk research (e.g., web sites, media reports, and press releases) to ensure credibility through triangulation (Jick, 1979). Two interview protocols were adopted, one with questions intended for executives (Annex 2A); one with questions intended for craftsmen and young employees (Annex 2B). Interviewees were encouraged to respond freely to the questions and to enrich their answers with additional information and personal feelings related to their working dimension to facilitate the story telling of their working experience and the description of the way they perceive their role, the knowledge management inside the organization and its transfer (Spradley, 1979). Specifically, craftsmen were asked to reflect on their key competences and the knowledge required to perform their tasks; how they acquired such knowledge and skills and how they transfer them to young employees.

The number of interviews has been determined in line with the theoretical saturation, i.e. interviews have been conducted with executive, craftsmen and young employees till the information gathered has been considered sufficient and no further relevant information could have been added by additional interviews (Strauss and Corbin, 1990). Overall, 8 executives (among which one chief executive officer, two plant production directors, two organization owners, one HR director and one administrative director); 7 craftsmen and 5 young employees were interviewed, for a total of 20 interviews over a sample of five organizations. Craftsmen and young employees to interview were selected with the support of the organizations' executives, in line with the intent and the objective of the research.

Consistent with the multiple-case analysis method (Eisenhardt, 1989), we began by synthesizing the data for each firm into individual case histories. Hence, data collected were analyzed for each case in isolation and condensed into a case write-up. Then, we asked to the interviewees to review their cases, which enabled us to complete the write-up and to eliminate some of the biases associated with retrospective interviews (Silverman, 2000). Once we had developed the individual case histories, we used them for two types of analysis: within-case and cross-case. Within-case analysis centered on uncovering how each organization realized the knowledge transfer process internally and how it managed its knowledge. After we had a good understanding of each case, we then began cross-case analysis to distill category-specific characteristics and corroborate the initial findings (Eisenhardt, 1989; Ozcan and Eisenhardt, 2009). Tables and color-coding were used to identify important similarities across 
the cases (Rafaeli and Vilnai, 2004). Then, we went back and forth between the initial findings and the original data to clarify specific details and to reach a consistent picture (Frankenberger et al., 2014).

Through the analysis of the information gathered, it was possible to answer to the research question and create a theoretical framework able to offer a process model of the knowledge transfer process in arts \& crafts organizations (see below, table 3 and 4).

\section{Findings and discussion}

To understand the role of craftsmen in arts \& crafts organizations, we identified the peculiarities of their knowledge to analyze how such knowledge is acquired and then transferred from one craftsman to another along either a tacit or a codified transfer process. Common patterns emerged from the empirical research that helped identify the craftsmen's key characteristics and that are in line with the ones identified by the academic literature (e.g., Stock et al., 2013; Lord and Ranft, 2000; O'Reilly et al., 1991) where the craftsman is described as a "masters of art", capable of using the "intelligence of the hand", the "passion of the heart" and the "creativity of the mind" (Shils, 1981; Schein, 2004) to acquire an aura of excellence and to confer exclusivity to products that enjoy a unique positioning in international markets (Sennett, 2008). It has indeed emerged that the craftsman is perceived as a fundamental resource for the organizations where he/she operates, able to add value to the artifacts he/she realizes through his/her unique skills and ability in the hand-made process.

We have briefly summarized the key features related to the craftsmen's knowledge deriving from the interviews' coding process and its triangulation with the literature review in Table 1; while the information collected with regard to the role and relevance of craftsmen for each organization has been summarized in Table 2.

\section{Insert Table 1}

\section{Insert Table 2}

Apart from the common peculiarities, the craftsman's specific role and function change according to each organization analyzed, where he/she can be perceived more as a symbol of the tradition and heritage of the organization (e.g., Organization R, organization B); as a master of the production process (e.g., Organization V, organization C); as source of creativity and inspiration (e.g., organization C); as a resource for the territory to which the organization belongs (e.g., organization RE, organization V); as the real differential value for the whole organization (e.g., organization B). It can therefore be recognized the craftsman's relevance within the arts $\&$ crafts organizations as the figure able to realize unique artifacts, expression of the tradition and heritage of the organization, as well as the depository of the relevant knowledge and skills which differentiate the organization from the competitive environment and confer exclusivity and uniqueness to its artifacts.

The above findings allowed to narrow the research on the knowledge transfer process within the arts \& crafts organizations, i.e. how the craftsmen's knowledge is being transferred. We hence tried to understand the ways through which knowledge transfer can be effective realized in line with the 
peculiarities of each organization, investigating the relationship among the exclusivity of the artifacts realized, the tradition and knowhow that each organization tries to preserve and transfer. This process helped understanding the effectiveness of the knowledge transfer for arts \& crafts organizations and to consolidate a holistic view on the overall knowledge transfer process with regard to (i) the specific knowledge to be transferred; (ii) the people (craftsmen) repository of such knowledge; (iii) the timing of the transfer; (iv) how the transfer is effectively realized; (v) the future of the knowledge transfer within the organization investigated.

\subsection{The specific knowledge to be transferred}

With regard to the specific knowledge to be transferred, the different organizations were aligned in answering that the knowledge to be transferred is the one that pertains to the hand-made skills and abilities of craftsmen, to which the tradition and peculiarities of each organization are related. Here are emblematic the words of the director of production of organization $\mathrm{V}$, according to whom "the kind of production process we adopt here, mainly hand-made, allows us to achieve a quality in the final artifact which is not replicable by any automated or serial production. On this specific quality we build our exclusivity and unique value proposition, which then allow us to sell our products to a very high price without suffering the competition from the mass market and from other premium brands which is known have automated or delocalized their production process. If we gave up the knowledge of our craftsmen replacing them with standardized production process, not only we would lose our heritage and exclusivity of our products, but we would lose also the prestige of our history and dissipate the value of our brand, hence to us is crucial to give maximum relevance to the knowledge of our craftsmen and find proper way to transfer it".

\subsection{The craftsmen repository of the knowledge to be transferred}

With regard to the craftsmen repository of the knowledge to be transferred, here the answers collected have shown different approach to the management of craftsmen activities and to the way their knowledge and knowhow is preserved and transferred. This is in line with the results of scholarly research on knowledge management and transfer, which reveals the complexity and multi-faceted nature of organizational knowledge, its management and transfer (Alavi and Leidner, 2001). Knowledge indeed, as highlighted in the literature review section, can be tacit or explicit, can refer to an object, a cognitive state or a capability, such the one of craftsmen. Thus, no single optimum approach to organizational knowledge management and transfer can be developed. With regard to the case studies here analyzed, the main difference that has emerged is that some organizations, for example Organization B, are trying to build an internal repository of knowhow, procedures and processes, writing internal manuals where the activities executed by craftsmen are transcribed so that new generation of employees have a physical place inside the organization where to go and read how to execute a specific task of the production process. This is done also through video recording of specific phase of the production process, so that 
seeing on screen the activities of experienced craftsmen can help new generation to learn and replicate their work. Here are of relevance the words of the Owner of Organization $\mathrm{B}$, according to whom "the main challenge we face regarding the activities performed by craftsmen is that such activities are not codified but are just passed over by craftsmen to new employees or colleagues. This let craftsmen decide on their own what to transfer and what to retain, mainly for their own proud, and most of all they are free to choose inside the organization to whom to transfer specific knowhow and skills, somehow basing their decision on their personal preferences. Hence my goal in the last years has been to codify the craftsmen's knowledge and skills, filming their work, having drawings, sketches and illustrations of the most peculiar phases of their manual activities and, at the end, allocating a specific area of our headquarters to become the physical repository of such knowledge, where different (and new) employees can access the repository of knowhow and skills which pertain to our organization". On the opposite side, other organizations, for example organization $\mathrm{C}$, do not care specifically about the role of craftsmen as repository of the knowledge to be transferred, simply they let craftsmen to manage in first person the knowledge transfer activities, without having a managerial commitment to guide such process. In this regard, one of the craftsmen working for Organization C clearly stated "there is no specific procedure to transfer knowledge, I simply sit down with other colleagues or new employees doing their apprenticeship here and tell them what to do and how to do it, showing the detailed phases of the whole production process. It is up to me decide how detailed I want to be in revealing the tricks of my activity and the extent that I want to give to the knowledge transfer process". Asked on the reason why the knowledge transfer is managed at craftsmen level and not at managerial level, preferably in a structured and eventually codified way, one manager of organization $\mathrm{C}$ simply replied that this is their modus operandi, it has always been like that since the establishment of the company more than fifty years ago and the craftsmen have always been great in performing their activities and passing over their skills to new generation of employees, so as a company they rely on this uncodified model and do not consider in the short term to change their knowledge management and transfer process.

\subsection{The timing of the knowledge transfer process}

With regard to the timing of the knowledge transfer process, here again our investigation proved that each organization adopts its own approach in transferring the skills and abilities of its craftsmen. For organization $\mathrm{V}$, for instance, time is of the essence for the activities performed by craftsmen, so new employees do not start their work until they have gained all the training and knowhow required to command properly the skills needed to realize excellent hand-made artifacts. For other organizations, for example organizations $\mathrm{RE}$ and $\mathrm{C}$, the timing of the knowledge transfer process starts when a new employee is put side by side to an experienced craftsman, who then spends some hours of his/her job to transfer his/her knowhow, showing manually how the job is performed and helping the new hired in his/her activities throughout the first months of employment. 


\subsection{How the transfer is effectively realized}

How the knowledge transfer is effectively realized was the most critical point to address, since each organization had its own point of view and process of knowledge transfer. This is in line with what observed by Crossan et al. (1999), who highlighted how the knowledge owners, i.e. the repository of the knowledge to be transferred, no longer think consciously about action. "Having been in the same, or similar, situations and recognizing the pattern, the expert knows, almost spontaneously, what to do. Indeed, if asked to explain their actions, experts may be unable to do so" (Crossan et al., p. 526). Knowledge to be transferred, therefore, in a simple way can be thought of as unconscious recollection. This helps explain why knowledge retained by craftsmen in arts \& crafts organizations is so hard to transfer from one person to another. It is indeed highly subjective, deeply rooted in individual experiences, and very difficult to surface, examine, and explain.

Organization B, for example, apart from building an internal repository of knowhow, procedures and processes as highlighted above in point (ii), is also partnering with external training schools to give more breadth and scope to the overall knowledge transfer process, with the intent of making the knowhow and skills of its craftsmen the main (intangible) asset of the organization. The goal of Organization B is indeed, as noted by the CEO, "to create an osmosis between the internal repository of knowhow and the external world of knowledge, represented by schools where to learn the theoretical construct and framework of the craftsmen activities, as well as new skills and modern technologies that may help refining and improving the overall production process, which remains mainly hand-made”. Attending external training courses would help indeed craftsmen to update their knowhow while remaining up-todate with all the aspects that characterize their work, this because if on one side working manually may not seem an activity subject to the technological obsolescence, on the other side technology helps craftsmen in several activities, e.g. the cutting of leather hides and the stitching phase of final products, hence specific training delivered by third parties may represent an opportunity to learn new skills that would help continuously increase the overall quality of the products realized. Organization RE, with this regard, has developed its own approach to knowledge transfer, institutionalizing the role of the "tutor", i.e. a craftsman, usually a senior with a proved field experience, responsible for transferring knowledge to the new generation of employees but also internally among other craftsmen. There is no formal coding of knowledge to be transferred, but at least Organization RE has institutionalized a modus operandi, according to which specific figures, i.e. tutors, are formally responsible for the overall knowledge transfer process and for coordinating the activities of new entrants or other employees within the organization. This approach, if on one side lacks all the formalities and the proper structure of a codified process, on the other side brings order inside the organization, recognizing in the tutor the figure with the official role of repository of the organizational knowhow, and hence the formal duty of transferring such knowhow to other employees. On the other hand, organization $\mathrm{V}$ in the transfer process very often relies also on the know-how and skills of former craftsmen who, even though already retired from their job, continue to act as mentor of young generation of employees, being involved in specific session 
where knowledge and skills are shared between the young generation and the old one, whose representatives are treated with great respect and consideration. Here the element that has emerged strongly is the relation of the organization with the territory where it is located and from which it hires new employees. As noted by Organization V's owner, indeed, "the link with the territory is our real competitive advantage and what preserves the uniqueness of our production process and the exclusivity of our products over the years and decades. The territory where we are located reflects and represents our history, the tradition and quality of our production process and is the reservoir of the young generation of employees. For these reasons having old craftsmen still part of the team, sharing their knowhow and skills with young generation of employees, is something that reinforce the link between our organization and the territory where it is located, a territory permeated with the knowhow and skills required to realize our unique and exclusive products.

\subsection{The future of the knowledge transfer within arts \& crafts organizations}

With regard to the future of the knowledge transfer within arts \& crafts organizations, it is emblematic here to mention the words of the Director of Production of Organization R, according to whom "today, notwithstanding there is a race for uniqueness, the arts \& crafts industry is trying to standardize its production to meet the tastes of the new rich, i.e. the Asian people, who tend to copy the American taste for style and exclusivity, which is replicated worldwide by the dominant class of the new rich and global elites. All our tradition of uniqueness and exclusivity, which derive directly from the Renaissance, if not understood and appreciated by our customers will finish to be dismissed and abandoned, so all the debate on knowledge transfer will be redundant if we do not really preserve the uniqueness and exclusivity of our heritage and culture that are then mirrored in the knowledge of craftsmen that we aim to transfer". This strong statement somehow has been the leit motiv of all the discussions with the people interviewed within the different organizations. The discussion on knowledge transfer, indeed, if on one hand pertains to the codification of the knowledge to be transferred and to the institutionalization of processes and procedures specific to such purpose, on the other hand it proves to have as objective a very fragile knowledge, which pertains to the past and brings along an exclusivity and uniqueness that tend not to be properly understood and appreciated by the new generation of customers. The future of the knowledge transfer in arts \& crafts organizations, hence, pertains to the future itself of these organizations. The knowledge they embody, indeed, being very often tacit and not codified, not only is difficult to transfer internally at production and processes level, but mainly it is difficult to transfer to final customers to increase their awareness of the exclusivity, complexity and uniqueness of the products such organizations realized.

In table 3 we have mapped the points (i) to (v) above analyzed as resulting from the interview process, while in table 4 we have summarized the key elements emerged from the interviews that help define the knowledge transfer process within arts \& crafts organizations.

\section{Insert Table 3}




\section{Insert Table 4}

\subsection{Concluding findings}

Generalizing the findings, it has emerged the importance of craftsmen within arts \& crafts organizations, whose know-how and technical skills are high valued by colleagues, by the market (customers), within the society and the territory where they operate. The knowledge acquired and retained by the craftsmen becomes therefore crucial for the survival of the arts \& crafts organizations and for their profitability in the long term. Nevertheless, from the empirical investigation it has emerged a certain unawareness at managerial level of the strategic relevance of the craftsmen knowhow and skills and of how to practically and effectively transfer their knowledge to a future generation of young craftsmen to continue to satisfy a unique and exclusive market demand. Specifically, we noted that managers tend not to be able to transfer the knowledge needed for long-term organization success. This is in line with Foos et al. (2006), according to whom while managers tend to see the value of tacit knowledge, there are different perceptions of the goals that a successful knowledge transfer shall achieve and a lack of processes to manage the knowledge transfer process itself. Furthermore, it has emerged the lack of a common knowledge transfer policy to different organizations, since each organization tends to define the premises, the objectives, the ways, the contents, the beneficiaries and the overall scope of its knowledge transfer process, in line with the strategic relevance it attributes to such process and to the peculiarities and personal characteristics of the craftsmen involved in the process, their specific know-how and role in the production of final artifacts. Therefore, it has not been possible to define a standard framework for the knowledge transfer process because it is influenced by the organizational structure, the management style of the organization owner (very often a family that retains the totality of the organization shares/quota), the social context and the territory where the organization is located, as well as the target market and the specific niche of customers who buy the organization's products. This result represents a potential threat for the survival of arts \& crafts organizations in the long run, especially when craftsmen are employees close to their retirement age and the young generation does not retain the same ability, skills and know-how to realize unique, hand-made artifacts. With this regard, the training of young generation, the codification of the craftsmen tacit knowledge and the establishment of specific repositories of knowledge, i.e. physical places within the organization where to store for example drawings, sketches and illustrations of the most peculiar phases of the craftsmen manual activities, can somehow help preventing the dissipation of craftsmen knowledge.

\section{Conclusion}

The present contribution, leveraging on the previous studies on knowledge and its transfer within organizations (e.g., Klamer, 2012; King et al., 2008; Tsoukas, 2005; Lambooy, 2002; Boisot, 2002; Nonaka and Teece, 2001; Rodgers et al. 2000; Dixon, 2000) has focused, through a multiple case studies methodology, on the analysis of the role of craftsmen in the knowledge transfer process within a specific 
sample of arts \& crafts organizations. This approach has been motivated by several elements that embrace both a theoretical perspective and a practical evidence. Indeed, as for the theory, despite the interest of many authors toward both knowledge management and transfer within the creative industry (Lampel and Germain, 2016; Seltzer and Bentley, 1999), there is a lack of studies aimed at linking systematically these two research areas specifically with regard to the subset of creative industry represented by the arts \& crafts organizations; as for the practice, there is as well a lack of practical understanding of the relationship between knowledge, knowledge transfer and the role played by craftsmen in the knowledge transfer process (Manfredi Latilla et al., 2018). Specifically, in a time where the business environment is constantly changing, the challenge for organizations is to manage the tension between the embedded learning from the past, which enables it to exploit learning, and the new learning that must be allowed to feed forward through the processes of a proper knowledge transfer (Crossan et al., 1999).

\subsection{Theoretical and practical contributions}

From the analysis, we have derived several arguments of debate relevant to craftsmen knowledge, their role within arts \& crafts organizations and the overall knowledge transfer process. A common result that has emerged is that craftsmen play a crucial role for the success of arts \& crafts organizations, since this kind of organization gives the maximum relevance to their individual abilities, knowhow and skills to generate wealth and employment through the creation and production of exclusive, high value products, hence it is crucial to preserve and transfer properly their knowhow and skills. This result is particularly relevant for the world of practice, in a time where globalization demands for the relocation of production processes and technology automates several job tasks, the variegated world of arts \& crafts, where the handmade abilities and skills of craftsmen cannot be replicate, imitate or standardize, becomes extremely important not only for culture, but also for the economy of a variety of countries among which Italy (Colombo, 2017; Busacca, 2013; Fortis, 2005).

With regard to the contribution to the academic research, we believe the present study may enrich the debate on the conceptualization and codification of knowledge transfer practices, where in our analysis has emerged the importance of creating ad hoc repositories and procedures to codify and favor such transfer, as well the role of training as a powerful tool to guide the young generation of craftsmen in performing properly their tasks in an organized and professional manner.

\subsection{Limitations and future directions of research}

Notwithstanding our attempt to provide contributions for both theory and practice, we are aware of the limitations of our study, since its exploratory nature and its relative small sample of analysis does not allow generalizing the findings to any population of arts \& crafts organizations. Accordingly, we invite future research into this subject to shed further light on the relationship between knowledge management and transfer in arts \& crafts organizations in a broader context, enlarging and 
differentiating the research sample to get a more omni-comprehensive view on the arts \& crafts organizations and on how they contribute to the diffusion and empowerment of a specific market niche made of high value and exclusive products. By pursuing its objectives indeed, this study aims to represent a step toward enabling arts $\&$ crafts organizations to play a vital role in the modern society in a more structured way. This would help build awareness of the potential of arts and crafts organizations for promoting economic growth, proposing a value proposition different from the one dictated by the globalization and by the triumph of product standardization and mass production. 


\section{References}

1. Ajith Kumar, J., \& Ganesh, L. S. (2009). Research on knowledge transfer in organizations: a morphology. Journal of Knowledge Management, 13(4), 161-174.

2. Alavi, M., \& Leidner, D. E. (2001). Knowledge management and knowledge management systems: Conceptual foundations and research issues. MIS quarterly, 25(1), 107-136.

3. Argote, L. and Ingram, P. (2000). Knowledge transfer: A basis for competitive advantage in firms. Organizational behavior and human decision processes, 82(1), 150-169.

4. Barney, J. B. (1986). Organizational Culture: Can It Be a Source of Sustained Competitive Advantage? The Academy of Management Review, 11(3), 656-665.

5. Berry, H. (2003), Leaders, laggards and the pursuit of foreign knowledge, Academy of Management

6. Best Conference Paper 2003, IM: D1-D6.

7. Boisot, M. (2002), The creation and sharing of knowledge. In Choo C.W. and Bontis N., The strategic management of intellectual capital and organizational knowledge, Oxford University Press.

8. Busacca, B. (2013). The Italy Brand: defending and strengthening its value. Available at: http://sdabocconi.it/it/news/2013/09/italy-brand-defending-and-strengthening-its-value [Accessed on July, $\left.12^{\text {th }}\right]$

9. Byles, C., Aupperle, K. and Arogyaswamy, B. (1991). Organizational Culture and Performance. Journal of Managerial Issues, 3(4), 512-527.

10. Chen, L. and Fong, P.S.W. (2015). Evaluation of knowledge management performance: an organic approach. Information \&Management, 52(4), 431-453

11. Cohen, M. and Bacdayan, P. (1994). Organizational routines as stored procedural memory: Evidence from a laboratory study. Organizational Science, 5(4), $554-568$.

12. Colombo P. (2007), La grande Europa dei mestieri d'arte. L'artigianato artistico d'eccellenza nei paesi dell'Unione Europea, Vita e Pensiero, Milano.

13. Corbin, J. M., and Strauss, A. (1990). Grounded theory research: Procedures, canons, and evaluative criteria. Qualitative sociology, 13(1), 3-21.

14. Cowan R., Foray D. (1996). The Changing Economics of Technological Learning, in Metcalfe et Vence, Wealth from Diversity, Kluwer.

15. Cowan, R., David, P. A., and Foray, D. (2000). The explicit economics of knowledge codification and tacitness. Industrial and corporate change, 9(2), 211-253.

16. Crossan, M. M., Lane, H. W., \& White, R. E. (1999). An organizational learning framework: From intuition to institution. Academy of Management Review, 24(3), 522-537.

17. Darr, E.D. and Kurtzberg, T.R. (2000), An investigation of partner similarity dimensions on knowledge

18. transfer, Organizational Behavior and Human Decision Processes, 82(1), 28-44.

19. Dasgupta, P. and David, P.A. (1994). Towards a New Economics of Science. Research Policy, 23, 487521.

20. Davenport, T.H. and Prusak L. (2000). Working Knowledge, Harvard Business School Press, Cambridge, Massachusetts.

21. David, P.A. and Foray, D. (1995). Accessing and expanding the science and technology knowledge base, STI Review, 16.

22. De Massis, A., Frattini, F. Kotlar, J, Messeni Petruzzelli, A. and Wright, M. (2016). Innovation through tradition: lessons from innovative family businesses and directions for future research. Academy of Management Perspectives, 30(1), 93-116.

23. Di Minin, A. and Faems, D. (2013). Building appropriation advantage: An introduction to the special issue on intellectual property management. California Management Review, 55(4), 7-14.

24. Dixon, N. M. (2000). Common knowledge: how companies thrive by sharing what they know, Harvard Business School Press, Cambridge, Massachusetts

25. Eisenhardt, K.M. (1989) Building theories from case study research. The Academy of Management Review, 14, 4, 532-550.

26. Fleming, D. (2001). Narrative leadership: Using the power of stories. Strategy \& Leadership, 29(4).

27. Foos, T., Schum, G., and Rothenberg, S. (2006). Tacit knowledge transfer and the knowledge disconnect. Journal of Knowledge Management, 10(1), 6-18.

28. Fortis, M. (2005). Il Made in Italy nel "nuovo mondo". Protagonisti, Sfide, Azioni, Rapporto Ministero delle Attività Produttive, Roma. Available at: 
http://www.symbola.net/din/adminphp/doc/Made $\% 20$ in $\% 20$ Italy\%20nel\%20nuovo\%20mondo $\% 20 \mathrm{Ma}$ rco\%20Fortis.pdf [Accessed on June, $19^{\text {th }}$ ]

29. Foss, N.J. and Pedersen, T. (2002), Transferring knowledge in MNCs: the role of sources of subsidiary

30. knowledge and organizational context, Journal of International Management, 8(1), 29-67.

31. Frankenberger, K., Weiblen, T. and Gassmann, O. (2014). The antecedents of open business models: an exploratory study of incumbent firms. R\&D Management, 44(2), 173-188.

32. Grant, R. M. (1996). Toward a knowledge-based theory of the firm. Strategic Management Journal, 17, 109-122.

33. Harlow, H. (2008). The effect of tacit knowledge on firm performance. Journal of Knowledge Management, 12(1), 148-163.

34. Heeley, M. B. and Jacobson, R. (2008). The recency of technological inputs and financial performance. Strategic Management Journal, 29(7), 723-744.

35. Hennekam, S. and Bennett, D. (2017). Creative industries work across multiple contexts: common themes and challenges. Personnel Review, 46(1), 68-85.

36. Høgseth, H.B. (2013). Knowledge transfer: the Craftmen's abstraction. Project Muse 4, 9780816599301, 61-78.

37. Huber, G.P. (1991). Organizational Learning: The Contributing Processes and the Literatures, Organization Science, 2(1), Special Issue: Organizational Learning: Papers in Honor of (and by) James G. March, 88-115.

38. Inkpen, A.C. and Tsang, E.W. (2005), Social capital, networks and knowledge transfer, Academy of

39. Management Review, 30(1), 146-65.

40. Jick, T.D. (1979) Mixing qualitative and quantitative methods: triangulation in action. Administrative Science Quarterly, 24, 4, 602-611.

41. Joia, L. A., and Lemos, B. (2010). Relevant factors for tacit knowledge transfer within organizations. Journal of Knowledge Management, 14(3), 410-427.

42. Kaufmann, J. C. (2004). L'invention de soi: une théorie de l'identité. Hachette. com.

43. King, W.R., Chung, T.R. and Haney, M.H. (2008). Knowledge Management and Organizational Learning. Omega, 36(2), 167-172.

44. Klamer, A. (2012). Crafting Culture: The importance of craftsmanship for the world of the arts and the economy at large. ACEI conference in Kyoto, Japan. Available at: http://klamer.nl/index.php/researchprojects/crafts/218-crafting-culture-the-importance-of-craftsmanship-for-the-world-of-the-arts-and-theeconomy-at-large-arjo-klamer-acei-conference-in-kyoto-japan-june-21-24-2012

45. Klammer, A. and Gueldenberg, S. (2018). Unlearning and Forgetting in Organizations: a Systematic Review of Literature. Journal of Knowledge Management, in press.

46. Koberg, C.S. and Chusmir, L.H. (1987). Organizational culture relationships with creativity and other job-related variables. Journal of Business Research, 15(5), 397-409.

47. Kotlar, J., De Massis, A, Wright, M. and Frattini, F. (2018). Organizational Goals: Antecedents, Formation Processes and Implications for Firm Behavior and Performance. International Journal of Management Reviews, 20(1), 3-18.

48. Lambooy, J.G. (2002). Knowledge and Urban Economic Development: An Evolutionary Perspective. Urban Studies, 36(5-6), 1019-1035.

49. Lampel, J. and Germain, O. (2016). Creative industries as hubs of new organizational and business practices. Journal of Business Research, 69(7), 2327-2333.

50. Levinthal, D. A. (1997). Adaptation on rugged landscapes. Management Science, 43(7), 934-950.

51. Levitt, B. and March, J. G. (1988). Organizational learning. Annual review of sociology, 319-340.

52. Lord, M.D. and Ranft, A.L. (2000). Organizational Learning about New International Markets: Exploring the Internal Transfer of Local Market Knowledge. Journal of International Business Studies, 31(4), 573-589.

53. Manfredi Latilla, V., Frattini, F., Messeni Petruzzelli, A. and Berner, M. (2018). Knowledge management, knowledge transfer and organizational performance in the arts and crafts industry: a literature review. Journal of Knowledge Management, 22(6), 1310-1331.

54. Messeni Petruzzelli, A. and Albino, V. (2012). When tradition turns into innovation. How firms can create and appropriate value through tradition. Oxford, UK: Woodhead Publishing Limited. 
55. Messeni Petruzzelli, A. and Savino, T. (2014). Search, recombination and innovation: lessons from haute cuisine. Long Range Planning, 47, 224-238.

56. Nelson, R.R. and Winter, S. (1982). An Evolutionary Theory of Economic Change. Harvard University Press, Cambridge, MA.

57. Nonaka I. (1994). A dynamic theory of organizational knowledge creation. Organization Science, 5(1), 14-37.

58. Nonaka I., Toyama R. and Nagata, A. (2000), A firm as a knowledge-creating entity: a new perspective on the theory of the firm, Industrial and Corporate Change, 9(1), 1-20.

59. Nonaka, I. and Takeuchi, H. (1995). The Knowledge Creating Company, Oxford University Press, New York.

60. Nonaka, I. and Teece, D.J. (2001). Managing industrial knowledge: creation, transfer and utilization, SAGE Publications, London.

61. O'Reilly III, C.A, Chatman, J. and Caldwell, D.F. (1991). People and organizational culture: A profile comparison approach to assessing person-organization fit. Academy of Management Journal, 34(3), 487516.

62. Osterloh, M. and Frey, B.S. (2000). Motivation, knowledge transfer, and organizational forms. Organization Science, 11(5), 538-550.

63. Ozcan, P. and Eisenhardt, K.M. (2009) Origin of alliance portfolios: entrepreneurs, network strategies, and firm performance. Academy of Management Journal, 52, 2, 246-279.

64. Pentland, B. T. (1995) Information Systems and Organizational Learning: The Social Epistemology of Organizational Knowledge Systems, Accounting, Management and Information Technologies, 5(1), 121.

65. Pratt, M. G. and Rafaeli, A. (1997). Organizational dress as a symbol of multilayered social identities. Academy of Management Journal, 40(4), 862-898.

66. Pratt, M. G. and Rafaeli, A. (2001). 3. Symbols as a language of organizational relationships. Research in Organizational Behavior, 23, 93-132.

67. Pulic, A. (1998), Measuring the performance of intellectual potential in the knowledge economy, $19^{\text {th }}$ Annual National Business Conference/Carver Tiffany, Hamilton, Stahlke, J. (Ed.), Ontario.

68. Rafaeli, A. and Vilnai-Yavetz, I. (2004). Emotion as a connection of physical artifacts and organizations. Organization Science, 15(6), 671-686.

69. Rafaeli, A. and Pratt, M.G. (2005). Artifacts and Organizations. Psychology Press.

70. Rodgers P. A., Caldwell, N. H., Clarkson, J. and Huxor, A. (2000). Managing knowledge in dispersed design companies. Facilitating context - driven design support through multiple perspectives. In J. S. Gero, Artificial intelligence in design '00, Kluwer Academic Publishers.

71. Savino, T., Messeni Petruzzelli, A. and Albino, V. (2017). Search and recombination process to innovate: A review of the empirical evidence and a research agenda. International Journal of Management Reviews, 19, 54-75

72. Schein, E. H. (1996). The missing concept in organization studies. Administrative Science Quarterly, 41(2), 229-240.

73. Schein, E. H. (2004). Organizational culture and leadership. New York: John Wiley \& Sons.

74. Seltzer K. and Bentley T. (1999). The creative age: knowledge and skills for the new economy. Demos, London.

75. Sennett R. (2008), The Craftsman, Yale University Press, New Haven.

76. Shils, E. (1981). Tradition. Chicago: University of Chicago Press.

77. Silverman, D. (2000) Doing Qualitative Research: A Practical Handbook. p. 316. London, UK: Sage.

78. Spradley, J. P. (1979). The ethnographic interview. Harcourt, Brace, Jovanovich

79. Stock, R., Six, B. and Zachari, N. (2013). Linking multiple layers of innovation-oriented corporate culture, product program innovativeness, and business performance: a contingency approach. Journal of Acad. Marketing Science, 41(3), 283-299.

80. Strauss, A. L. and Corbin, J. (1990). Basics of qualitative research (Vol. 15). Newbury Park, CA: Sage publications.

81. Tsoukas, H. (2003). Do we really understand tacit knowledge? In E.-S. M. \& L. M. A., The Blackwell handbook of organizational learning and knowledge management, Backwell Publishing 
82. Venkitachalam, K. and Busch, P. (2012). Tacit knowledge: review and possible research directions. Journal of Knowledge Management, 16(2), 356-371.

83. Von Krogh, G. Ichijo, K. and Nonaka, I. (2000). Enabling knowledge creation. How to unlock the mystery of tacit knowledge and release the power of innovation. New York: Oxford University Press.

84. Watson, S. and Hewett, K. (2006), A multi-theoretical model of knowledge transfer in organizations:

85. determinants of knowledge contribution and knowledge reuse, Journal of Management Studies, 43(2), 141-73.

86. Yin, R.K. (2009) Case study research: design and methods. 4th edn. Thousand Oaks, CA: Sage Publications. 